九州大学学術情報リポジトリ

Kyushu University Institutional Repository

\title{
Development of an Intelligent Robot for an Agricultural Production Ecosystem (III) - Modeling of the Predation of Rice Plants and Weeds by Golden Apple Snail -
}

Luna Maldonado, Alejandro Isabel

Laboratory of Agricultural Ecology, Division of Agricultural Ecology, Graduate School of Bioresources and Bioenvironmental Sciences, Kyushu University

Yamaguchi, Yusuke

Laboratory of Agricultural Ecology, Division of Agricultural Ecology, Graduate School of Bioresources and Bioenvironmental Sciences, Kyushu University

Tuda, Midori

Institute of Biological Control, Faculty of Agriculture of Kyushu, University

Nakaji, Ke i

Laboratory of Agricultural Ecology, Division of Agricultural Ecology, Department of Plant Resources, Faculty of Agriculture, Kyushu University

https://doi.org/10.5109/12867

出版情報: 九州大学大学院農学研究院紀要. 53 (2)，pp.517-521，2008-10-28. Faculty of Agriculture, Kyushu University

バージョン：

権利関係: 


\title{
Development of an Intelligent Robot for an Agricultural Production Ecosystem (III) - Modeling of the Predation of Rice Plants and Weeds by Golden Apple Snail -
}

\author{
Alejandro Isabel LUNA MALDONADO ${ }^{1}$, Yusuke YAMAGUCHI ${ }^{1}$, \\ Midori TUDA ${ }^{2}$ and Kei NAKAJI*
}

\author{
Laboratory of Agricultural Ecology, Division of Agricultural Ecology, Department of \\ Plant Resources, Faculty of Agriculture, Kyushu University, \\ Fukuoka 811-2307, Japan \\ (Received June 27, 2008 and accepted July 16, 2008)
}

\begin{abstract}
Models of the predation of rice plants and weeds by golden apple snails based on the Lotka- Volterra equations and the equations of Holling are introduced in this researching. These prediction equations are useful to estimate the number of snails in different phases of the rice crop season; however they should be modified to fit better to the rice production ecosystem and then this information will be used for the agricultural production robot in order to make decisions about the appropriate timing for removing the snails in excess in paddy field.
\end{abstract}

\section{INTRODUCTION}

In the ecosystem of the paddy, the golden apple snails are serious invaders in Asian paddy. The snails cause immediate damage to the young seedlings especially in conservation agriculture. In the Figure 1, the snails voraciously eat rice plants just transplanted at Kyushu University Farm. The farm work to remove snails is tedious and the hand picking of snails consumes more than two hours per 10 a (Kunimoto and Nishikawa, 2008). In this researching, the number of snails is predicted in different phases of the paddy field using the LotkaVolterra and Holling equations in order to develop an intelligent robot which executes the tasks of controlling of weeds and snails in the paddy.

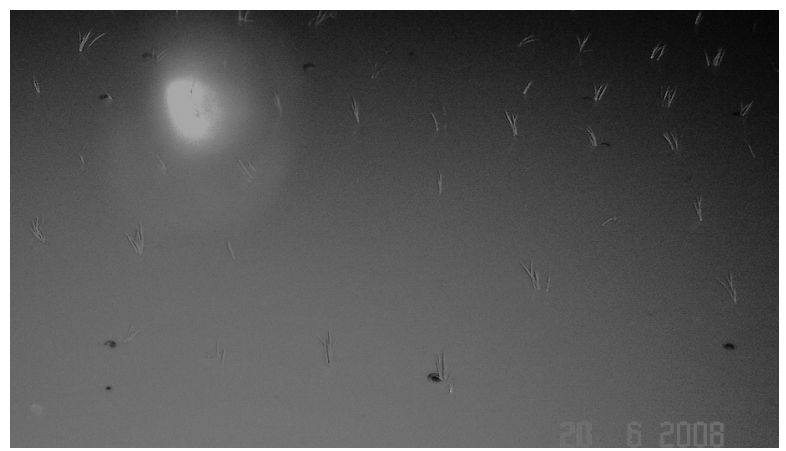

Fig. 1. Predation of rice plants immediately after transplanting in lowland paddy field at Kyushu University Farm on the night of June $20^{\text {th }}, 2008$.

\footnotetext{
${ }^{1}$ Laboratory of Agricultural Ecology, Division of Agricultural Ecology, Graduate School of Bioresources and Bioenvironmental Sciences, Kyushu University

${ }^{2}$ Institute of Biological Control, Faculty of Agriculture of Kyushu University

* Corresponding author (E-mail: knkjfam@mbox.nc.kyushu-u. ac.jp)
}

\section{PREDATION MODEL IN THE AGRICULTURAL PRODUCTION ECOSYSTEM}

In natural ecosystems we can see the behavior of the snails and superior plants (weeds or rice plants) according to the Lotka-Volterra model (Lotka, 1925, Volterra, 1926) as shown in Figure 2. We used the Lotka-Volterra equations considering the different works in the paddy for the farmers to do over the season of the crop in order to predict the populations of snails or biomasses of rice plants and weeds. We should understand the farm works in the artificial ecosystem of the paddy and establish the initial conditions to model the ecosystem of the paddy.

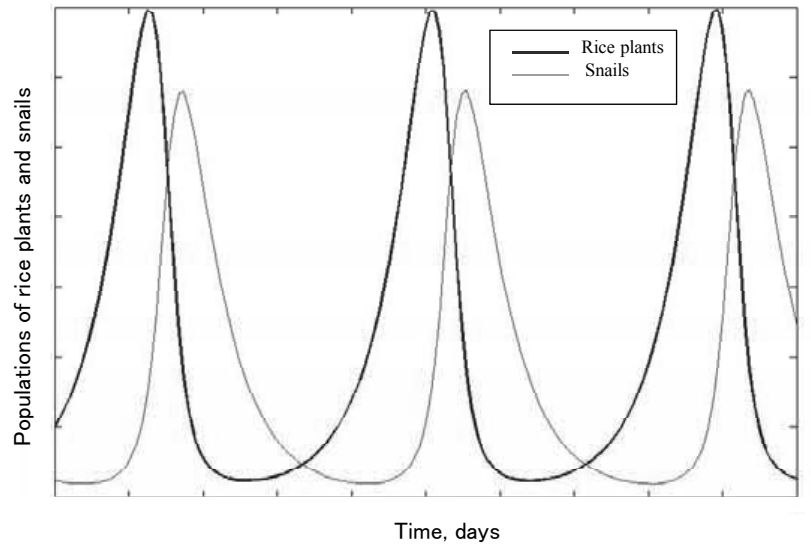

Fig. 2. Populations of plants and snails in a natural ecosystem based on Lotka-Volterra model.

Model for growth rate of plants and snails based on the equations of Lotka-Volterra

Our models are based on the equations of LotkaVolterra are as follows

$$
\frac{d N}{d t}=r N-a S N
$$




$$
\frac{d S}{d t}=b S N-m S
$$

Where, $N$ : total density or biomass of superior plants (rice plants and weeds), $S$ : density of snails, $r$ : intrinsic rate for superior plants, $b=f \cdot a$ : reproduction rate of snails per 1 plant eaten, $f$ : the rate at which snails turn plants into offspring, $a$ : predation rate coefficient, i.e., is the search rate or attack efficiency of snails, $m$ : snails mortality rate of snails.

To understand the predation dynamics ecologically we examine solutions at equilibrium analytically and get the isoclines as follows

$$
\begin{aligned}
& N(r-a S)=0 \\
& S(b N-m)=0
\end{aligned}
$$

\section{Jacobian Matrix for snails and weeds}

If $J(N, S)$ is a fixed point, we can use the equations 1 and 2 when growth rates are zero and then construct a Jacobian matrix.

$$
\begin{aligned}
& \frac{d N}{d t}=r N-a S N \\
& 0=r N-a S N \\
& \frac{d S}{d t}=b S N-m S \\
& 0=b S N-m S
\end{aligned}
$$

Then we define the system of differential equations using the equations 5 and 6 .

$$
J(N, S)=\left|\begin{array}{cc}
\frac{\partial(E q 5)}{\partial N} & \frac{\partial(E q 5)}{\partial S} \\
\frac{\partial(E q 6)}{\partial N} & \frac{\partial(E q 6)}{\partial S}
\end{array}\right|
$$

And we do linearization in order to find the Jacobian of the vector function of the nonlinear system. We get the rendered general Jacobian matrix for snail and rice plants in predation as follows,

$$
J(N, S)=\left[\begin{array}{cc}
r-a S & -a N \\
b S & b N-m
\end{array}\right]
$$

By using the equations 3 and 4, we have two solutions for the equation 3 as follows $N=0$ or $S=r / a$. From the equation 4 we have the following roots: $S=0$ and $N=m / b$, so the equilibrium points are the following: $P_{1}(0,0)$ and $P_{2}(m / b, r / a)$

We analyzed the stability of the system by the evaluation of the Jacobian matrix in each fixed points, $P_{1}$ and $P_{2}$.

$$
\begin{aligned}
& \text { In } P_{1} \\
& J(0,0)=\left[\begin{array}{cc}
r-a \cdot 0 & -a \cdot 0 \\
b \cdot 0 & b \cdot 0-m
\end{array}\right]
\end{aligned}
$$

$$
J(0,0)=\left[\begin{array}{cc}
r & 0 \\
0 & -m
\end{array}\right]
$$

The eigenvalues and eigenvectors in $P_{1}$ are as follow

$$
\lambda_{1}=r, \lambda_{2}=-m, \xi_{1}=\left(\begin{array}{l}
1 \\
0
\end{array}\right), \xi_{2}=\left(\begin{array}{l}
1 \\
0
\end{array}\right)
$$

In $P_{2}$

$$
\begin{aligned}
& J(m / b, r / a)=\left[\begin{array}{cc}
r-a \cdot \frac{r}{a} & -a \cdot \frac{m}{b} \\
b \cdot \frac{r}{a} & b \cdot \frac{m}{b}-m
\end{array}\right] \\
& J(m / b, r / a)=\left[\begin{array}{cc}
0 & -\frac{a m}{b} \\
\frac{b r}{a} & 0
\end{array}\right]
\end{aligned}
$$

The eigenvalues and eigenvectors $P_{2}$ are as follows

$$
\lambda_{1}=r, \lambda_{2}=-m, \xi_{1}=\left(\begin{array}{l}
1 \\
0
\end{array}\right), \xi_{2}=\left(\begin{array}{l}
1 \\
0
\end{array}\right)
$$

or

$$
\lambda= \pm \sqrt{a_{1} b_{1}} \equiv \pm i w
$$

Models for the populations of snails based on Lotka-Volterra equations in different phases of the agricultural production ecosystem of paddy in Kyushu University Farm

The main phases of the agricultural production of the paddy were described by Luna Maldonado and Nakaji (2008) and these are the models for those stages based on Lotka-Volterra equations for predation.

After tillage,

$$
\frac{d S}{d t}=0
$$

After rice paddling,

$$
\frac{d S}{d t}=C
$$

Where $C$ : constant.

After transplanting,

$$
\frac{d S}{d t}=b N_{1} S-m S
$$

Where, $S$ : density of snails, $b$ : reproduction rate of snails, $N_{1}$ : density of superior plants (rice plants and weeds), $m$ : mortality rate of snails.

Ten days after transplanting,

$$
\frac{d S}{d t}=b S\left(N_{1}+N_{2}+N_{3}\right)-m S
$$

$N_{2}$ : density of Tamagayatsuri, $N_{3}$ : density of Azena, After rice plants have reached $40 \mathrm{~cm}$ of height,

$$
\frac{d S}{d t}=b S\left(N_{2}+N_{3}\right)-m S
$$


Model for growth rate of superior plants (rice plants and weeds) based on the equation of Holling

We can analyze what happens after transplanting of rice seedlings in the farm (Figure 3). We have in the rice field an initial amount of rice plants transplanted by the farmers. The snails, introduced by irrigation before paddling, start to eat the rice plants and the population of plants decreases where as the population of snails increase rapidly. After ten days the weeds will show up in the rice plot and the snails start to eat the weeds and the population of plants will keep almost constant. The snail's population still grows up until the populations of weeds start to decline, and then the snails suffered of hunger, therefore the population of snails will reduce, until the weeds will show up again in the field.

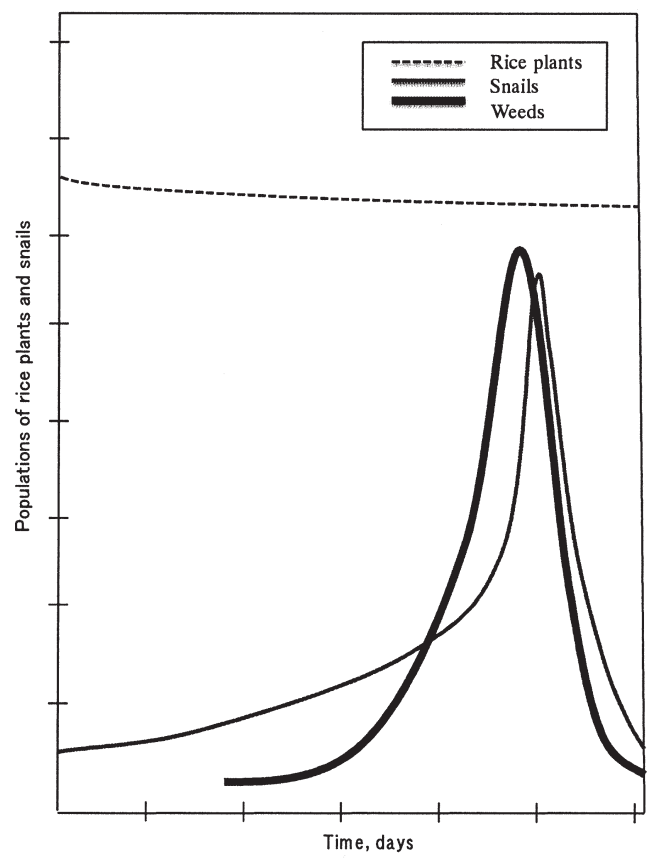

Fig. 3. Population dynamics of rice plants, snails and weeds in the agricultural production of paddy in lowland at Kyushu University Farm.

The Holling equation is an extension of the equation of Lotka-Volterra that adds a functional response (changes in the predation as prey's density increases). We considered the equations of Holling Type II (Holling, 1959 ) in order to fit our models to the agricultural production ecosystem as follows.

$$
\frac{d N}{d t}=r N\left(1-\frac{N}{K}\right)-\frac{p N S}{1+a N}
$$

Where, $r$ : intrinsic rate for superior plants (rice plants or weeds) in the paddy, $N$ : total density or biomass of superior plants (rice plants and weeds), $K$ : carrying capacity of superior plants, $p$ : predation rate of superior plants by snails, $S$ is the density of snails and $a$ : predation rate coefficient, which is the search rate or attack efficiency of snails.

The equation 13 can be expressed as follows

$$
\frac{d N}{d t}=-\frac{r N^{2}}{K}+r N-\frac{p N S}{1+a N}
$$

Isocline

$$
\begin{aligned}
& \frac{d N}{d t}=0 \\
& 0=-\frac{r N^{2}}{K}+r N-\frac{p N S}{1+a N}
\end{aligned}
$$

There are three possible equilibrium solutions for $\mathrm{N}$ as follows

$$
N=0
$$

or

$$
N=\frac{a\left(r k a-r \pm \sqrt{r^{2} k^{2} a^{2}+2 r^{2} k a+r^{2}-4 r a p S k}\right)}{2 r}
$$

and

$$
S=\frac{r}{p}(1+a N)\left(1+\frac{N}{K}\right)
$$

Model for growth rate of snails based on the equation of Holling

$$
\frac{d S}{d t}=\frac{b N S}{1+a N}-m S
$$

Where, $b$ : reproduction rate of snails and $m$ : mortality rate of snails.

Isocline

$$
\begin{aligned}
& \frac{d S}{d t}=0 \\
& 0=\frac{b N S}{1+a N}-m S
\end{aligned}
$$

The equilibrium solution is as follows

$$
S=0
$$

and

$$
N=\frac{m}{b-m a}
$$

\section{Jacobian Matrix for snail and superior plants}

If $J(N, S)$ is a fixed point, we can use the equations 13 and 17 when growth rates are zero and then construct a Jacobian matrix.

$$
\begin{aligned}
& \frac{d N}{d t}=r N\left(1-\frac{N}{K}\right)-\frac{p N S}{1+a N} \\
& 0=-\frac{r N^{2}}{K}+r N-\frac{p N S}{1+a N} \\
& \frac{d S}{d t}=\frac{p N S}{1+a N}-m S
\end{aligned}
$$




$$
0=-\frac{p N S}{1+a N}-m S
$$

Then we define the system of differential equations using the equations 20 and 21 .

$$
J(N, S)=\left|\begin{array}{ll}
\frac{\partial(E q 20)}{\partial N} & \frac{\partial(E q 20)}{\partial S} \\
\frac{\partial(E q 21)}{\partial N} & \frac{\partial(E q 21)}{\partial S}
\end{array}\right|
$$

And we do linearization in order to find the Jacobian of the vector function of the nonlinear system. We get the rendered general Jacobian matrix for snails and superior plants as follows,

$J(N, S)=\left|\begin{array}{c}-\frac{2 r N}{K}+r-\frac{p S}{1+a N}+\frac{a p N S}{(1+a N)^{2}}-\frac{p N}{1+a N} \\ \frac{b S}{1+a N}-\frac{a b N S}{(1+a N)^{2}} \quad \frac{b N}{1+a N}-m\end{array}\right|$

Models for the populations of snails based on Holling equations in different phases of the agricultural production ecosystem of paddy in Kyushu University Farm.

After tillage,

$$
\frac{d S}{d t}=0
$$

After rice paddling,

$$
\frac{d S}{d t}=C
$$

Where $C$ : constant.

After transplanting,

$$
\frac{d S}{d t}=\frac{b N_{1} S}{1+a N}-m S
$$

Where, $S$ : density of snails, $b$ : reproduction rate of snails, $N_{1}$ : density of rice plants and $m$ : mortality rate of snails. Ten days after transplanting,

$$
\frac{d S}{d t}=\frac{b\left(N_{1}+N_{2}+N_{3}\right) S}{1+a N}-m S
$$

$N_{2}$ : density of Tamagayatsuri, $N_{3}$ : density of Azena, After rice plants have reached $40 \mathrm{~cm}$ of height,

$$
\frac{d S}{d t}=\frac{b\left(N_{2}+N_{3}\right) S}{1+a N}-m S
$$

After transplanting, the initial conditions were $N=742$, $S=100, r=1, K=750, p=0.002, a=0.1, b=0.012$ and $m=0.1$ we can get the chart of the Figure 4 using the equation of Holling. In this phase of the rice crop season the weeds have not shown up in the agricultural production ecosystem. The snails start to eat young rice plants. We can also see from the Figure 4 that population of rice plants increased a little bit from 742 to 760 according to

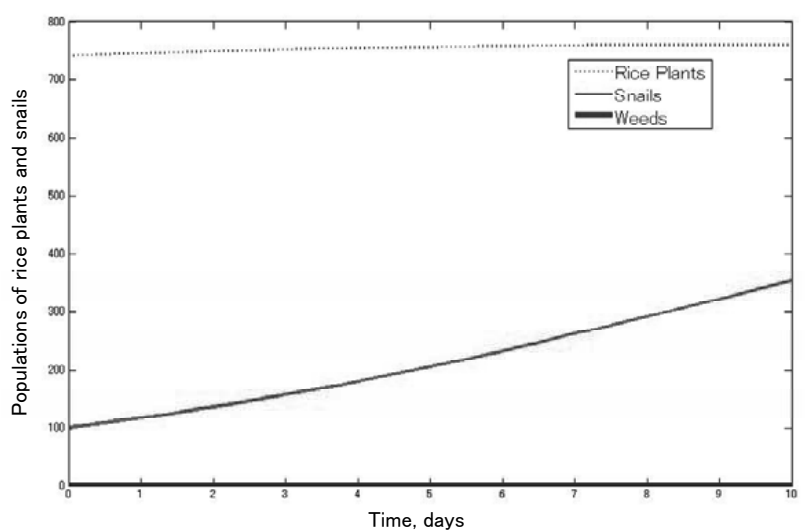

Fig. 4. Population dynamics of snails, rice plants and none weeds during day 1 to day 10 after transplanting in a lot of 50 square meters.

the model used for ten days after transplanting.

We obtained the chart of the Figure 5 considering from day 10 to day 100 after transplanting. The initial conditions were $N=760, S=353, W=1 \quad r=1, K=750$, $p=0.002, a=0.1, b=0.012$ and $m=0.1$. Where $W$ : population of weeds. In this phase of the rice crop season the weeds have shown up in the agricultural production ecosystem and snails eat both rice plants and weeds.

Using the equations $14,15,16,19$ and 20, we can obtain the general equations of the stationary points by substitution of the $N$ and $S$ in the general Jacobian equation 23 and then get the eigenvalues.

We analyzed the populations of plants and snails in one of the fixed points by using Holling equations and found that $N=50$ and $S=400$, and the Jacobian matrix is as follows,

$$
J\left(P_{1}\right)=\left[\begin{array}{cc}
1.642 & -0.019 \\
0.0002 & 0.018
\end{array}\right]
$$

The eigenvalues are: $\lambda_{1}=1.640, \lambda_{2}=0.018$, therefore that point is unstable.

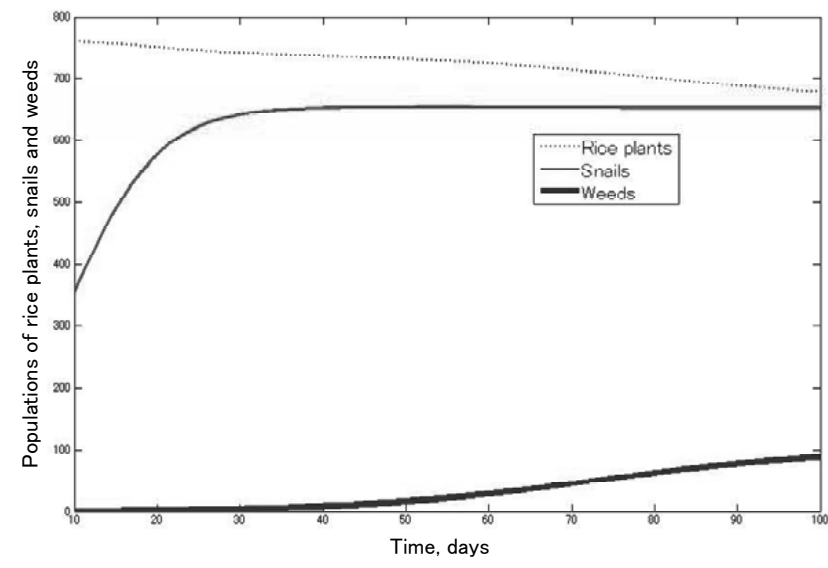

Fig. 5. Population dynamics of snails, rice plants and weeds from day 10 to day 100 after transplanting in a lot of 50 square meters. 


\section{DISCUSSION}

The Lotka-Volterra and Holling equations estimate quantitatively the populations of snails and plants; however, we should consider the different stages over the crop season and make models that fit to those phases of the ecosystem of rice production. Using the equations of Holling we found that the first ten days after transplanting, the population of rice plants increased a little bit and then became stable, however in the ecosystem of paddy, the snails consume rice plants and therefore the density of rice plants should be decreased and then becomes stable.

In analysis of one the fixed points, $N=50$ and $S=400$; however in the agricultural production ecosystem they should be about $N=730$ and $S=2$.

\section{CONCLUSION}

The biodiversity of the agricultural production ecosystem will be enriched by through the prediction of the number of snails to be removed of paddy in the different phases of crop season. The models based on the equations of Lotka-Volterra and Holling considered the different farm works; however those models should be modified in order to fit better to the ecosystem of rice production. It is also necessary to model the agricultural production ecosystem considering factors, such as tem- perature, light and water depth.

\section{REFERENCES}

Gotelli, N. J. 1998 A Primer of Ecology, 2nd edition. Sinauer Associates, Inc. Sunderland, MA, USA, pp. 125-153

Holling, C. S. 1959 The components of predation as revealed by a study of small mammal predation of the European Pine Sawfly. Canadian Entomologist, 91: 293-320

Keeling, M. J., H. B. Wilson and S. W. Pacala 2002 Deterministic limits to stochastic spatial models of natural enemies. The American Naturalist, 159: 57-80

Kunimoto, Y. and M. Nishikawa 2008 Improvement of the Catch Efficiency of the Apple Snail, Pomacea canaliculata (Lamarck) (Gastropoda:Ampullariidae) by the Trap Crop. Japanese Journal of Farm Work Research, 43: 75-82

Lotka, A. J. 1925 Elements of Physical Biology. Williams and Willkins Co, Baltimore, USA

Luna Maldonado, A. I. and K. Nakaji 2008 Development of an Intelligent Robot for an Agricultural Production EcosystemNew Concept of Robot and Dynamics of a Golden Apple Snail in Paddy-. Journal of the Faculty of Agriculture, Kyushu University, 53: 115-119

Luna Maldonado, A. I., Y. Yamaguchi, M. Tuda and K. Nakaji 2008 Development of an Intelligent Robot for an Agricultural Production Ecosystem (II) - Modeling of the Competition between rice plants and weeds -. Journal of the Faculty of Agriculture, Kyushu University, 53: 511-516

Volterra V. 1926 Variazioni e fluttuazioni del numero d'individui in specie animali conviventi. Memorie della $R$. Accademia Nazionale dei Lincei, 54: 31-113 